\title{
INCLUSÃO ESCOLAR: ALGUMAS DISCUSSÕES EM EDUCAÇÃO MATEMÁTICA
}

\author{
Erica Aparecida Capasio ROSA ${ }^{1}$ \\ Ivete Maria BARALDI ${ }^{2}$
}

Resumo: Este artigo apresenta considerações sobre legislações, dissertações e teses defendidas no Programa de Pós-Graduação em Educação Matemática que discutem essa temática e algumas reflexões sobre inclusão escolar a partir de recortes das narrativas de professores que ensinam matemática de um município do estado de São Paulo, participantes da pesquisa de E. Rosa (2014). Em tal pesquisa foram entrevistados nove professores, sendo sete professores de Matemática e duas professoras de Educação Especial. Para constituir essas narrativas foi utilizada como metodologia a da História Oral. Ao final concluímos que quando estamos falando sobre inclusão escolar, estamos falando de outro "modelo de escola", pois este em que as professoras relatam e que aí está continua à excluir, até mesmo inconscientemente as pessoas com deficiência, transtorno global do desenvolvimento, altas habilidades e superdotação.

Palavras-chave: Educação matemática inclusiva. Escola. Alunos com deficiência. Professores. Narrativas.

\section{Introdução}

Na Educação Matemática, a inclusão de alunos com deficiência ou necessidades educativas especiais ${ }^{3}$ em escolas regulares é tema de constantes debates devido ao desafio que representa. Historicamente, a luta das pessoas com deficiência foi marcada por sacrifício, abandono, lágrimas, torturas, experimentos, segregação, preconceito e exclusão pela sociedade. Desde o início do século 1920, algumas práticas foram se solidificando com a intenção de reverter essa situação, por exemplo, a criação de políticas públicas que valorizam as singularidades e o desenvolvimento de princípios inclusivos, sobretudo em nossas instituições escolares.

A Declaração de Salamanca (Espanha), há 20 anos, apresentou uma visão diferenciada de educação especial, proclamando que as escolas regulares deveriam ser

1 Doutoranda em Educação Matemática. UNESP - Universidade Estadual Paulista. Instituto de Geociências e Ciências Exatas - Pós Graduação em Educação Matemática. Rio Claro - SP - Brasil. 13506-900 - erica.cap.rosa@gmail.com

${ }^{2}$ UNESP - Universidade Estadual Paulista. Faculdade de Ciências - Departamento de Matemática. Bauru - SP - Brasil. 17033-360 - ivete.baraldi@fc.unesp.br

${ }^{3}$ A expressão "necessidades educativas especiais" se refere ao indivíduo com ou sem deficiência que requer um auxílio educacional diferenciado devido a apresentar dificuldades na aprendizagem. 
inclusivas e que a indicação de instituições especializadas para o ensino de crianças com deficiências deve ser exceção e não regra (BRASIL, 1994a). Assim, todas as crianças devem estar na escola e a mesma deve ter condições de lidar com a diversidade de sua clientela. $\mathrm{O}$ atendimento às crianças com deficiência não deve ser o "de serviço", ou seja, apenas são fornecidas condições para que elas se integrem ao ambiente escolar ou à sociedade, adaptando-se. A escola deve fornecer um atendimento "de suporte", aquele que preconiza que as diferenças são características humanas, sendo, portanto, necessário modificar e adaptar o ambiente para as pessoas com deficiências (ROMERO; SOUZA, 2008). Decorrente da Declaração, no Brasil, várias outras leis, resoluções e decretos foram oficializados, entre os quais apontamos alguns a seguir.

Em 2002, a Resolução do Conselho de Educação/Conselho Pleno nº 1/2002 que instituiu as Diretrizes Curriculares Nacionais para a Formação de Professores da Educação Básica, em nível superior, curso de licenciatura, de graduação plena- definiu que as instituições de ensino superior devem prever em sua organização curricular, entre outros itens, o conhecimento sobre o desenvolvimento humano e contemplar especificidades dos alunos com necessidades educacionais especiais, com deficiência (visual, auditiva, física, mental), transtornos globais do desenvolvimento e altas habilidades ou superdotação, ou, ainda, alunos advindos de comunidades indígenas (BRASIL, 2002).

Ainda em 2002, a Língua Brasileira de Sinais (Libras) foi reconhecida como língua oficial do surdo, sendo a Língua Portuguesa sua segunda língua. Esse reconhecimento por lei implicou a obrigatoriedade de seu ensino nos cursos de formação de fonoaudiólogos e professores de nível médio e superior, por meio do Decreto 5.626 de 22 de dezembro de 2005 (BRASIL, 2005). O uso, o ensino, a produção e a difusão do Sistema Braille, em todas as modalidades de ensino, foram aprovados e normatizados pela Portaria $\mathrm{n}^{\mathrm{o}} 2.678 / 02$.

Em 2003, o Ministério da Educação (MEC) criou o Programa Educação Inclusiva: direito à diversidade, que visa apoiar a formação de gestores e educadores, a fim de transformar os sistemas educacionais em sistemas educacionais inclusivos. Esse programa ainda está em funcionamento.

Em 2004, foi promulgado o documento "O Acesso de Alunos com Deficiência às Escolas e Classes Comuns da Rede Regular” (BRASIL, 2004, p. 5) que teve por objetivo "divulgar os conceitos mais atuais e adequados às diretrizes mundiais de inclusão da pessoa com deficiência na área educacional.” 
No ano de 2006, foi aprovada pela ONU (Organizações das Nações Unidas) a "Convenção sobre os Direitos das Pessoas com Deficiência" a qual estabelece que os Estados “[...] devem assegurar um sistema de educação inclusiva em todos os níveis de ensino, em ambientes que maximizem o desenvolvimento acadêmico e social compatível com a meta de inclusão plena.” (BRASIL, 2009, p.1).

Em 2008, foi divulgada uma versão da Política Nacional de Educação Especial na perspectiva da Educação Inclusiva, a qual prevê o atendimento especializado em salas de recursos e centros especializados de referência. A educação especial direciona suas ações para o atendimento às especificidades dos alunos no processo educacional e, no âmbito de uma atuação mais ampla na escola. Ainda prevê a organização de redes de apoio, a formação continuada, a identificação de recursos, serviços e o desenvolvimento de práticas colaborativas para os professores (BRASIL, 2008).

Em 2011, tem-se o Decreto relacionado à educação inclusiva de $n^{0} 7.611$, que dispõe sobre a educação especial e o atendimento educacional especializado (AEE) e que assegura a educação aos alunos com deficiências, preferencialmente, nas redes regulares de ensino:

Deve integrar a proposta pedagógica da escola, envolver a participação da família para garantir pleno acesso e participação dos estudantes, atender às necessidades específicas das pessoas públicoalvo da educação especial, e ser realizado em articulação com as demais políticas públicas. (BRASIL, 2011, p.1).

Em meados de 2014, foi aprovado o Plano Nacional de Educação (PNE) que tem a vigência para os próximos 10 anos, e nesse plano há 10 diretrizes e 20 metas para serem cumpridas, entre essas existem algumas que são dedicadas à educação inclusiva, por exemplo, a superação das desigualdades educacionais e a erradicação de todas as formas de discriminação, como também:

Universalizar, para a população de 4 (quatro) a 17 (dezessete) anos com deficiência, transtornos globais do desenvolvimento e altas habilidades e superdotação, o acesso à educação básica e ao atendimento educacional especializado, preferencialmente na rede regular de ensino, com a garantia de sistema educacional inclusivo, de salas de recursos multifuncionais, classes, escolas ou serviços especializados, público ou conveniados. (BRASIL, 2014, p. 6). 
Nesses vinte anos, em termos de políticas públicas em relação à educação especial, o Brasil teve que garantir, por meio de leis e programas de apoio financeiro e técnico, a orientação dos sistemas de ensino, favorecendo a formação de professores para o atendimento educacional especializado e de demais profissionais da educação para a inclusão escolar.

Ainda, gostaríamos de destacar que no Censo Escolar de 2012 (BRASIL, 2012) nota-se que as matrículas da modalidade Educação Especial estão concentradas nas escolas públicas e que há, principalmente, um movimento de redução de matrículas nas classes especiais e escolas especiais, e um crescente aumento nas classes comuns. Em 2007, eram 348.470 alunos em classes especiais e 306.136 alunos incluídos em classes comuns. Já em 2012, ocorreu uma alteração grande nesses números: o número de alunos nas classes especiais caiu para 199.656 e aumentou consideravelmente o número de alunos incluídos para 620.777. No Censo Escolar de 2014 publicado pelo INEP (Instituto Nacional de Estudos e Pesquisas Educacionais Anísio Teixeira) ${ }^{4}$ nota-se a continuação de diminuição de matrículas de alunos com deficiência, transtorno global do desenvolvimento, altas habilidades e superdotação sendo atualmente $172.226 \mathrm{em}$ instituições especiais. Mas, o que os professores (de Matemática) que estão em sala de aula estão vivenciando? Como estão trabalhando, seja em termos de práticas ou de conceitos, com os alunos incluídos? Qual é a formação inicial ou continuada que os professores possuem para trabalhar com a inclusão? Será que a escola que aí está é inclusiva?

Diante do exposto, o trabalho de E. Rosa (2014) teve como objetivo elaborar compreensões a partir de narrativas de professores que ensinam Matemática sobre a inclusão escolar e o processo de ensino e a aprendizagem de Matemática de alunos com deficiência. Dessa forma, neste artigo, nossa intenção é a de mostrarmos um recorte de tal pesquisa, enfocando as discussões que pudemos realizar acerca da inclusão escolar.

\section{Considerações sobre algumas pesquisas em educação matemática inclusiva.}

Passos, Passos e Arruda (2013), após analisarem quatro importantes periódicos da área, concluíram que, até aquele momento, poucas eram as pesquisas sobre inclusão nas aulas de Matemática e que as publicações estavam centradas na aprendizagem do aluno com deficiência. Anteriormente, Mendes (2008) ao revisar 29 pesquisas

\footnotetext{
${ }^{4}$ Para maiores informações acesse: < http://portal.inep.gov.br/basica-censo>. Acesso em: 24 nov. 2015.
} 
realizadas no Grupo de Pesquisa "Formação de Recursos Humanos em Educação Especial" que pertence ao Programa de Pós Graduação da UFSCar de Educação Especial, verificou que existiam poucas pesquisas que abordavam o ensino fundamental II e o cotidiano escolar de um professor de área específica.

No Programa de Pós-Graduação em Educação Matemática da Unesp, Rio Claro, até meados de 2015, foram computados onze trabalhos que discutem essa temática. Um primeiro trabalho é o de Oliveira (1993) que teve como objetivo “[...] apresentar uma proposta alternativa de atividades para a pré-alfabetização matemática de crianças com deficiência auditiva, tendo como enfoque principal, a construção do pensamento lógicomatemático dessas crianças.” Após 13 anos, Lírio (2006, p. 5) defendeu seu trabalho que pretendeu “[...] conhecer as possibilidades e limitações do uso de tecnologia informática para o ensino de geometria para cegos."

Em 2008, Calore (2008, p.6) finalizou sua pesquisa que tinha por objetivo: "descrever e analisar o ser, o saber, e o fazer de sujeitos cegos em instituições de ensino". E Rodrigues (2008, p.5) também defendeu sua dissertação que tinha como objetivo "[...] observar, descrever e analisar como os professores que ensinam matemática lidam com alunos em uma escola inclusiva."

Marcelly (2010, p.7) trabalhou com alunos cegos com o objetivo de: “[...] analisar o processo de construção e adaptação de uma História em Quadrinhos sobre Matemática para alunos cegos e videntes [...]”. Marcone (2010) disparou uma discussão sobre a inclusão escolar no ensino Superior, especificamente sobre o ensino de matemática.

Há pouco tempo, no ano de 2013, foram defendidas duas pesquisas. Uma dissertação abordando a formação do professor de matemática e como ele se aproxima da inclusão (ROSA, F., 2013); e uma tese que investigou como a visualidade da pessoa surda pode contribuir para o ensino e a aprendizagem matemática (SALES, 2013). No ano de 2014, tivemos mais dois trabalhos discutindo essa temática: a dissertação de E. Rosa (2014), cujo objetivo era o de elaborar uma compreensão, por meio das narrativas de professores que ensinam matemática, sobre a inclusão escolar e o processo de ensino e a aprendizagem de Matemática de alunos com deficiência; e a outra que investigou “[...] possibilidades de atuação do professor na sala de recursos, no processo de ensino e de aprendizagem de matemática de crianças com deficiências.” (HILSDORF, 2014, p.6). 
Até abril de 2015, foram defendidos mais dois outros trabalhos na perspectiva da educação inclusiva, a tese que teve como questão diretriz discutir pessoas com deficiência, justiça social e educação matemática (MARCONE, 2015, p.5). E uma dissertação que teve como objetivo "estabelecer uma compreensão sobre o engajamento de crianças surdas em uma proposta de cenários para investigação", ou seja, buscou-se investigar se esse ambiente possibilita “[...] discussões matemáticas, bem como de que forma a matemática pode contribuir para a autonomia e inclusão social de pessoas com deficiência, com enfoque nas pessoas surdas." (MOURA, 2015, p.7). Ao início de outubro desse mesmo ano (2015) temos a defesa da Tese de Lessandra Marcelly, que discutiu possibilidades de um ensino de matemática para todos inseridos em uma escola, especificamente para estudantes cegos.

Assim, percebemos que são ainda escassos os trabalhos que abordam inclusão escolar de alunos com deficiência em Educação Matemática, mas que há uma crescente oferta de estudos nessa área, como tentamos esboçar, levando em consideração um determinado programa de pós-graduação.

Iremos nos deter um pouco mais no trabalho de Rosa (2014), do qual efetuamos esse recorte apresentado. Esta pesquisa teve como pergunta diretriz "O que os professores que ensinam matemática dizem sobre a inclusão escolar e o ensino e a aprendizagem de matemática para os alunos que são público alvo da Educação Especial?” A dissertação foi composta por nove narrativas de professores que ensinam Matemática na rede municipal de Campinas - São Paulo. As narrativas foram produzidas a partir da metodologia qualitativa, História Oral. Os pressupostos dessa metodologia, utilizados pelo Grupo História Oral e Educação Matemática (Ghoem), do qual a pesquisadora pertence, também foram trabalhados na pesquisa. Neste trabalho, foram construídas três categorias de análise, as narrativas: "À primeira vista", "Formação" e "Que escola é essa?". Nelas, foram discutidas as sensações narradas pelos professores entrevistados ao entrar pela primeira vez em sua sala de aula e perceber a existência de alunos com deficiência, bem como as sensações das professoras de educação especial ao ter que ensinar conteúdos matemáticos referentes aos anos do Ensino Fundamental II, o que não estudaram em sua formação pedagógica. Considerações foram tecidas acerca da formação dos professores que ensinam matemática sob a perspectiva da educação inclusiva. E por último, foi discutido o tema de inclusão escolar e educação matemática. Dessa forma, por meio deste nosso estudo, torna-se possível apresentarmos as discussões a seguir. 


\title{
Educação matemática e inclusão escolar: uma compreensão
}

\author{
Entendemos escola como
}

[...] um espaço de busca, construção, diálogo e confronto, prazer, desafio, conquista de espaço, descoberta de diferentes possibilidades de expressão e linguagens, aventura, organização cidadã, afirmação da dimensão ética e política de todo processo educativo [...] (CANDAU, 2007, p. 15).

Ainda, conforme Moreira e Candau (2003, p.160), podemos definir a escola como sendo uma "[...] instituição construída historicamente no contexto da modernidade e tem como função sócio fundamental: transmitir cultura, oferecer as novas gerações o que de mais significativo culturalmente se produziu na humanidade." Dessa maneira, passando a ser concebida como um espaço de cruzamento, conflitos, diálogos entre diferentes culturas. Deve-se "[...] olhar para a escola como um espaço de diversidade e respeitar tal espaço com o compromisso de ensinar seus indivíduos de modo a serem críticos na sociedade em que vivem [...]” (ROSA, E., 2014, p. 127).

Ainda para Candau (2003, p.24), a escola é "palco de diferentes relações sociais e reflete a diversidade cultural presente na sociedade" e, em seu cotidiano, é desafiada a trabalhar com todos os aspectos que compõem a cultura, tais como visões de mundo, estilos de vida, crenças, costumes, etnias, cores, bem como administrar os problemas decorrentes da diversidade cultural dos seus alunos e profissionais. Atualmente, para essa autora, também é imprescindível "repensar a cultura da sala de aula e romper com o 'congelamento' que a escola sofreu através do tempo" (CANDAU, 2000, p. 76). Ao usar o termo congelamento, está se referindo aos métodos de ensino e a aprendizagem tradicionais.

A professora $\mathrm{M}^{5}$ narra um trecho de um dos grandes desafios encontrados na escola, pois se tem

[...] todas as mazelas, todo tipo de problema, aluno que passa fome, aluno que é molestado por familiares, aluno que tem pais presos, aluno que viu pais morrerem. E quanto mais a escola está inserida numa realidade social mais pobre ou uma comunidade com mais problemas. A questão da droga é muito forte, e quanto mais esse aluno está inserido nestes problemas, mas difícil é a escola [...]

Excerto da narrativa de M em E. Rosa (2014, p. 99).

${ }^{5} \mathrm{~A}$ professora M escolheu ser mencionada dessa maneira na pesquisa de E. Rosa (2014), pois optou por manter o anonimato. A sua formação inicial é em Licenciatura Matemática e leciona há 13 anos no município em que foi realizada a pesquisa. 
E é nessa mesma escola em que os alunos, público alvo da educação especial, devem ser incluídos, não apenas educacionalmente, mas socialmente. Dessa forma, para termos uma escola inclusiva, ou seja, uma escola "apta" a receber todos os alunos da diversidade brasileira, como nos alerta a professora $\mathrm{M}$ é aquela que:

Deveria ter vários profissionais nos ajudando: psicólogo, médico, psicopedagogo, outro colega atuando junto na sala de aula... As diferenças estão chegando e numa mesma sala de aula você tem aluno que não pode mais ser reprovado, e não sabe ler ou até consegue ler, mas não consegue interpretar. São muitos tipos de diferença numa mesma sala. E o professor não consegue dar conta.

Excerto da narrativa da Professora M em E. Rosa (2014, p. 98).

Para tanto é preciso uma "transformação na estrutura física, organizacional, pedagógica e filosófica das escolas” (PLETSCH, 2010, p. 13), com “[...] acessibilidade, flexibilidade escolar, práticas pedagógicas diferenciadas de ensino e avaliação, e, principalmente, uma equipe de professores e gestores capacitados para lidar com a diversidade dos estilos de aprendizagem e demandas de seu alunado [...]" (PLETSCH, 2010, p. 129). Além da participação de todos nesse processo: do professor, da família, da coordenação pedagógica e, principalmente, dos órgãos governamentais.

Para se ter uma educação inclusiva é necessário que

[...] a inclusão esteja presente na conjuntura do desenvolvimento da escola, permeando todas as políticas, de forma que estas aumentem a participação e a aprendizagem de todos os alunos. O paradigma educacional atual demanda políticas educacionais que contemplem os anseios exigidos nas diversas áreas da educação. Nesse contexto, a implantação das políticas públicas de educação inclusiva no âmbito educacional é relevante, pois contribui efetivamente com uma educação que fará a diferença. (SILVA; SANTOS, 2014, p. 216).

Atualmente, a escola que aí está, pensamos, não consegue cumprir com suas funções já definidas e se tornar inclusiva. Os professores entrevistados se mostraram favoráveis à inclusão escolar, porém resistentes a alguns aspectos, por exemplo, falta de apoio dos poderes públicos para realizar um bom trabalho. Alguns professores não concordam, pois acreditam que a aprendizagem deles seria melhor em um ambiente segregado das salas de aulas regulares. Essa mesma opinião também pode ser constatada na pesquisa de O’Brien e O’Brien (1999, p.48). “Esses alunos sempre foram 
educados junto com outros semelhantes a ele. [...] Ter esses alunos aqui conosco vai nos desviar do nosso propósito real e destruir nossa rotina [...]”".

Além do mais, as sensações dos docentes são diversas ao se depararem com um aluno com deficiência. Nas narrativas dos professores, independente de quantos anos de experiência na docência eles tinham, percebemos certa insegurança ao relatarem quando se deparam com alunos com deficiência em sua sala de aula, ou seja, estes professores retratam suas primeiras percepções “[...] apresentando sentimentos de insegurança, medo, despreparo profissional, e busca de equilíbrio das suas contradições entre seus princípios e ideais pessoais construídos ao longo do processo de formação [...]" (ROCHA; FIORENTINI, 2009, p. 127).

Em sua narrativa, Gabriela ${ }^{6}$ nos mostra ter pela primeira vez um aluno com deficiência visual, um aluno não ideal, que talvez não tenha sido lhe apresentado no seu curso de formação inicial ou continuada, ficou muito assustada e insegura e se expressou dizendo "Como é que eu vou fazer?" e depois complementou "Mas logo no primeiro dia eu já percebi que não era um problema para mim, porque ele conseguia acompanhar melhor que os outros alunos". A mesma sensação pode ser percebida no relato do professor João quando diz: "O primeiro impacto que tive foi muito forte". Uma resposta mais enfática foi da professora Elisabeth ${ }^{8}$ ao dizer que foi apavorante e “até sentia um pouco de rejeição, e pensava: 'Não quero, não quero!' e aí fui lidando com essa situação no dia a dia".

A professora Fabiana ${ }^{9}$, embora não fale muito de suas sensações, declara encarar os alunos com deficiência como um desafio e que é, mesmo assim, receosa diante da diversidade que existe em sua sala de aula. Ainda, em sua narrativa transparece a desorientação do professor para trabalhar com alunos com deficiência quando expressa: “Como que vai ser? Como que eles vão conseguir aprender?”. A mesma falta de

\footnotetext{
${ }^{6}$ A professora Gabriela escolheu ser mencionada dessa maneira na pesquisa de E. Rosa (2014), pois optou por manter o anonimato. A sua formação inicial é em Licenciatura em Matemática e leciona há 20 anos no município da cidade em que foi realizada a pesquisa.

${ }^{7}$ O professor João escolheu ser mencionado dessa maneira na pesquisa de E. Rosa (2014), pois optou por manter o anonimato. A sua formação inicial é em Administração e depois formou-se em Matemática. Leciona há 10 anos no município da cidade em que foi realizada a pesquisa.

${ }^{8}$ A professora Elizabeth escolheu ser mencionada dessa maneira na pesquisa de E. Rosa (2014), pois optou por manter o anonimato. A sua formação inicial é em Licenciatura em Matemática e leciona há 19 anos no munícipio da cidade em que foi realizada a pesquisa.

${ }^{9}$ A professora Fabiana escolheu ser mencionada dessa maneira na pesquisa de E. Rosa (2014), pois optou por manter o anonimato. A sua formação inicial é em Licenciatura em Matemática e leciona há 10 anos no município da cidade em que foi realizada a pesquisa.
} 
orientação também é perceptível na narrativa da professora Maria ${ }^{10}$ ao se perguntar: "Meu Deus, o que eu faço agora?".

Algumas pesquisas divulgadas pelo MEC em 2009 mostraram que 96,5\% dos estudantes, pais e mães, professores da Rede Pública de Ensino do País têm preconceito e querem manter distância de pessoas com deficiência. E em outra pesquisa mostra-se que $96 \%$ dos professores se dizem despreparados para a inclusão escolar (OSÓRIO, 2010). Estes relatos corroboram o trabalho de Vitaliano e Valente (2010). quando dizem que os professores não foram preparados para a inclusão de alunos com deficiência e que muitas vezes, a presença destes em suas salas de aulas têm se constituídos em um problema que lhes têm gerado 'stress', sentimento de impotência e outras consequências percebidas como negativas.

Alguns professores descreveram suas reações de maneira mais tranquila, como a professora $\mathrm{M}$ ao afirmar que não teve problemas ao observar pela primeira vez que possuía um aluno surdo em sua sala, principalmente depois de perceber que ele não apresentava dificuldades em Matemática. Dessa maneira, a única coisa que fez de diferente em suas aulas convencionais foi ensinar olhando para ele, para que conseguisse fazer a leitura labial.

A professora $\mathrm{Sol}^{11}$ nos contou que ficou um pouco receosa no início, porém como acredita na fé espírita e entende que o aluno com deficiência "é um espirito que não está evoluído moralmente, mas intelectualmente, e ele é mais do que a gente, ele está ali numa condição que limitou ele por algum motivo de outras vidas", conseguiu lidar com essa situação de outras maneiras. Ao nos determos um pouco mais nessa narrativa, percebemos que ela nos remete às crenças existentes desde a Idade Média, quando as pessoas com deficiência "ganharam alma e, eliminá-las ou abandoná-las significava atentar contra os desígnios da divindade" (RODRIGUES, 2008, p. 8). Entender as deficiências dessa maneira ainda é frequente na sociedade, pois $31,95 \%$ dos trabalhadores de uma rede de supermercados, entrevistados para uma pesquisa com o objetivo de investigar as concepções sobre inclusão de pessoas com deficiência no ambiente profissional, acreditam que essas indivíduos devem ser respeitadas por caridade em uma visão espiritual (BRITE; SOBRINHO; CASTELÕES, 2010).

\footnotetext{
${ }^{10}$ A professora Maria escolheu ser mencionada dessa maneira na pesquisa de E. Rosa (2014), pois optou por manter o anonimato. A sua formação inicial é em Licenciatura em Matemática e leciona há 13 anos no município da cidade em que foi realizada a pesquisa.

${ }^{11}$ A professora Sol escolheu ser mencionada dessa maneira na pesquisa de E. Rosa (2014), pois optou por manter o anonimato. A sua formação inicial é em Licenciatura em Matemática e leciona há 15 anos no munícipio da cidade em que foi realizada a pesquisa.
} 
Ao lermos as narrativas, além de percebermos resistência de alguns professores em aceitar os alunos com deficiência, é perceptível que os próprios colegas de sala também reforçam o estigma, por exemplo, na narrativa de Maria, quando fala sobre a relação das outras crianças em sala em relação a um aluno com autismo a quem lecionou: "[...] ele avançou na aceitação do grupo, hoje a sala já o aceita mais, os alunos fazem menos brincadeiras sem graça com ele, por exemplo, colocar chiclete na cadeira dele, dar papel para ele comer, entre outras [...]" (ROSA, 2014, p.105) mesmo Maria orientando as crianças "para não deixá-lo sozinho, que não é para fazer por ele" (ROSA, 2014, p.105). A professora Elizabeth fala das pessoas com deficiência com um sentimento de pena, o que não contribui muito para a questão da inclusão escolar delas.

\begin{abstract}
Antigamente, eu percebia que os alunos defendiam mais o aluno com deficiência, atualmente as crianças são mais perversas, essa é a impressão que eu tenho. E perversa, por exemplo, o fato de elas saberem que o D é autista, eu já vi eles batendo na cabeça dele, não protegendo. Nessa escola, já tivemos vários alunos com deficiência e tivemos aluno que levava o coleguinha que usava a cadeira de roda para o lanche. Atualmente, com esses dois alunos, só uma vez que eu vi um coleguinha convidando-os para o lanche, os outros não, saem correndo e esquecem deles. A professora de Educação Especial sempre vai buscá-los, sempre ficam sentadinhos e não vão na onda das crianças, se eu deixar eles ficam o tempo todo sentadinhos na sala de aula. É triste de ver isso, mas é assim a todo o momento.

Excerto da Narrativa de Elizabeth em E. Rosa (2014, p. 73).
\end{abstract}

É visível aqui, ainda, a necessidade de se ter caridade com a pessoa com deficiências, pois utiliza muitas palavras no diminutivo, mostrando sua sensibilidade com a situação, mas sem uma intenção clara de ação educacional.

No entanto, percebemos que alguns professores, como Salete e João, entendem que as resistências quanto à inclusão estão mudando e que o professor trabalha muito mais tranquilo com a questão do aluno com deficiência, completam dizendo que hoje ninguém mais exclui ou não quer trabalhar com esses alunos. Entendemos essas afirmações como ingênuas diante da realidade e do cotidiano escolar, das próprias narrativas que constituíram nosso trabalho, bem como também abordado por F. Rosa (2013). Nas narrativas dos professores permeia o conceito de que a pessoa com deficiência é incapaz de aprender, é limitado e impossibilitado. Isso nos revela que, existe um olhar tradicional para a pessoa com deficiência, partindo da "[...] ideia de que o defeito significa menos, falha, deficiência, limita e estreita o desenvolvimento da criança, o qual era caracterizado, antes de mais nada, pelo ângulo da perda dessa ou 
daquela função [...]”. (VIGOTSKI, 1995, p. 869) ${ }^{12}$. Sobre isso, Vigotski apresenta uma outra compreensão, partindo da posição de que a deficiência exerce uma dupla influência do seu desenvolvimento por um lado "produzindo falhas, obstáculos, dificuldades da adaptação (VIGOTSKI, 1995, p. 869)", e por outro, "servindo de estímulo para o desenvolvimento de caminhos alternativos de adaptação (VIGOTSKI, 1995, p. 869)”. Desse modo, Vigotski (1995, p. 869) “[...] prescreve que se considere não apenas as características negativas da criança, mas também um retrato positivo de sua personalidade." Assim, também é possível observar nas narrativas dos professores, ao descreverem a primeira vez que percebem que tem um aluno com deficiência em sua sala de aula, que o subestimam em relação ao conteúdo (matemático), ficando surpreendidos, em alguns casos, quando estes são melhores que os alunos considerados "normais". Muitas vezes, é comum o professor pensar que o aluno com deficiência auditiva, por exemplo, também terá grandes dificuldades de aprendizagem matemática, mas deveria ter ciência de que a criança com deficiência não é menos desenvolvida que as outras crianças sem deficiência, mas sim, uma criança que se desenvolve de uma forma diferente (BENDES, 2010).

As narrativas das professoras que ensinam Matemática nos revelam outra faceta da inclusão escolar e que atinge aos professores de Educação Especial: a insegurança não está em trabalhar com alunos com deficiência e sim com conteúdos que não dominam, por exemplo, os conteúdos matemáticos referentes ao Ensino Fundamental II. Clarice ${ }^{13}$ afirma que: "Não sou boa de matemática, então, tinha medo de ensinar [...]" e a professora Salete ${ }^{14}$, alerta que:

[...] o município oferece cursos semestralmente que trabalha diversas áreas de atuação dos professores em que trabalhava a adaptação de materiais concretos, em 2009. Um desses cursos foi o de metodologia da Matemática, esse curso foi bem legal, porque não era um curso voltado só para a questão da deficiência e adaptações era voltado para os professores.

Excerto na narrativa de Salete em E. Rosa (2014, p.56).

${ }^{12}$ Tradução feita por Denise Regina Sales, Marta Kohl de Oliveira e Priscila Nascimento Marques do texto Vigotski (1995).

${ }^{13}$ A professora Clarice escolheu ser mencionada dessa maneira na pesquisa de E. Rosa (2014), pois optou por manter o anonimato. A sua formação inicial é em Educação Especial com habilitação em deficiência intelectual pela Universidade Metodista de Piracicaba e leciona há 11 anos no munícipio da cidade em que foi realizada a pesquisa.

${ }^{14} \mathrm{~A}$ professora Salete escolheu ser mencionada dessa maneira na pesquisa de E. Rosa (2014), pois optou por manter o anonimato. A sua formação inicial é Pedagogia com habilitação em deficiência intelectual pela Universidade Estadual de Campinas e leciona há 15 anos no munícipio da cidade em que foi realizada a pesquisa. 
Dessa forma, percebemos que os professores que possuem a formação específica para o ensino dos conteúdos matemáticos, ou seja, aqueles que possuem Licenciatura em Matemática, não têm formação para trabalhar com alunos com deficiência. Por outro lado, os professores de Educação Especial, geralmente, formados em Pedagogia, que possuem a formação para ensinar os alunos com deficiência, não possuem formação suficiente para auxiliar em alguns conteúdos específicos, no caso dessa investigação, os de Matemática.

Silva e Santos (2014, p. 226) nos alerta que:

\begin{abstract}
Se pensarmos em formar professores voltados para uma orientação inclusiva, que se percebam e atuem como sujeitos capacitados, não se pode perder de vista a necessidade de propiciar momentos na formação inicial e continuada para discussão e reflexão da realidade excludente em que vivemos e a necessidade cada vez maior de práticas que visem à desconstrução de culturas de exclusão, propiciando a fomentação de políticas institucionais e públicas de uma educação de qualidade para todos. Trata-se de uma luta pela efetivação de uma educação inclusiva, que traz a valorização das diferenças, que respeita o aluno na sua singularidade. Esse princípio obriga os professores a suprimir toda forma de homogeneidade em suas práticas e a construir novas competências para um fazer pedagógico que contemple princípios inclusivos de práticas eficazes.
\end{abstract}

Ainda, Vitalino e Valente (2010), corroboram que uma prática reflexiva auxilia o professor a lidar melhor com as dificuldades do cotidiano escolar, e nesse viés, talvez uma solução para esse impasse, de ambos os medos e inseguranças, seria a colaboração entre os professores, momentos de reflexões e cooperação entre todos os responsáveis pelo ensino dentro das suas unidades escolares. Um trabalho colaborativo entre as partes é de fundamental importância para se construir uma escola inclusiva que a sociedade deseja.

Mas, este trabalho colaborativo não pode ser notado nas narrativas, muito pelo contrário. O professor da classe regular não entende o papel do professor de educação especial, delegando a ele somente o sucesso de aprendizagem do aluno com deficiência que tem necessidades educativas especiais. Muitas vezes, o aluno com tais necessidades fica excluído na sala de aula de Matemática.

Nas narrativas dos professores não encontramos palavras segregação, marginalização, exclusão, porém, ao narrar suas ações no cotidiano escolar, as 
identificamos, mesmo que o docente não tenha clareza delas e que atua exercitando-as, como destacamos a seguir

No meu terceiro colegial eu tenho um aluno que eu não sei qual o problema dele, usa a cadeira de roda e ele não tem movimentação, fica parado e só move a cabeça. Eu não faço trabalho algum com ele. Até isso acaba sendo um descuido meu, mas como é terceiro ano, em uma escola particular, e estamos preparando os alunos para o vestibular, eu não tenho muito tempo a perder. Tenho o conteúdo para seguir e ele fica na frente, só olhando, não escreve nada. Ele está no terceiro ano porque ele vai passando, como tem o laudo, a nota dele já vai direto seis para o boletim, é um aluno ouvinte. [...]. Para alguns as provas são diferentes, mas para esse meu aluno nem prova diferente eu faço, porque ele não faz. Ele está só de ouvinte, eu até não perguntei o que é o caso dele. Mas eu não sei qual é e fala com dificuldades também. Eu pergunto: "tudo bem?" ele responde: "tudo bem." Responde a chamada: "presente". Os outros alunos destravam a cadeira dele para ele sair. Quando os alunos estão fazendo prova, ele está ali também esperando todo mundo fazer prova. Aí acabou a prova, os alunos destravam a cadeira dele para ele sair. Mas ele não faz. Acho que é mais para ter um convívio social mesmo. Ele possui poucos movimentos nas mãos, eu não sei se para comer alguém dá comida para ele. Eu acho que ele conseguiria digitar, se fosse fazer alguma coisa, seria digitar. Ninguém fez nenhum trabalho com ele e como eu só trabalhei com ele no terceiro ano, já está encerrando, vou seguindo como está. Porque se ele já tivesse alguma coisa, já era para ter tido nos anos anteriores, e já ia chegar com ele algum computador. E ele não é novo na escola, estava lá no ano passado. É feito um trabalho com ele, às vezes, porque a escola tem o professor de educação especial, no outro período, mas ali dentro da sala de aula não. Nas conversas que eu tive com o professor de educação especial eu não perguntei dele, porque eu vejo que ele não faz nada ...até é uma falha minha porque eu deveria até perguntar para ver se é feito algum trabalho diferente com ele. Até vou perguntar como uma curiosidade para saber. Mas, realmente, teria que ver o que mais, além disso, o aluno faz. Porque talvez daria para ele fazer alguma coisa no computador, eu acredito. Não sei se ele paga a mensalidade da escola, é que lá tem muitos bolsistas, pode ser que ele seja e esteja lá só por um convívio.

Excerto da narrativa de Fabiana em E. Rosa (2014, p.79).

As narrativas dos professores nos mostram que eles estão confusos quando o assunto é inclusão escolar e, talvez, não perceberam que necessitam rever suas práticas e seus conceitos em relação aos alunos com deficiências em suas salas de aulas. Os professores ainda não possuem clareza de que para desfazer dos preconceitos, discriminação, estigmas, "[...] exige que tenhamos consciência clara e corajosa de que estamos aprisionados e de que nossa luta deve ir além da defesa de uma escola para todos [...]” (PADILHA 2014, p. 107). 
Os medos, as ansiedades, as preocupações e as divergentes opiniões e pensamentos, nos permitem vislumbrar que ainda faltam formação e ação do poder público para efetivar um novo paradigma educacional, mas proposto há mais de vinte anos. Diante do exposto, ousamos afirmar que a maioria das escolas ainda não está preparada para incluir alunos com deficiência, transtorno global do desenvolvimento, altas habilidades e superdotação, além de toda a diversidade que possa existir. Ainda, que há necessidade de que as políticas públicas sejam efetivadas, pois temos uma legislação que preconiza que o ensino inclusivo é um direito básico e essencial para todos os alunos.

Cabe lembrar que a constituição de uma política pública educacional bem definida por si só não é suficiente: sua efetivação requer trabalho. É preciso criar uma cultura inclusiva em que os princípios construídos sejam a base norteadora tanto das decisões políticas quanto das práticas. (SILVA; SANTOS, 2014, p. 224).

Por fim, nesse artigo tivemos a intenção de apresentar uma discussão sobre a inclusão escolar de alunos com deficiência inseridos nas salas de aulas a partir de narrativas de professores que ensinam matemática, colaboradores da pesquisa de E. Rosa (2014).

Ao longo do texto, é possível perceber que os professores entrevistados mostram-se favorável a inclusão escolar, porém são resistentes a alguns aspectos, por exemplo, falta de apoio das pessoas que participam do ambiente escolar, como coordenadores pedagógicos, direção, merendeira, faxineira, inspetor de alunos, secretária, professores, alunos e família além dos poderes públicos para realizar um bom trabalho. Diante disso, alguns professores chegam a acreditar que os alunos público alvo da educação especial necessitam ficar em salas separadas dos demais para que ocorra a aprendizagem (matemática).

Diante desse panorama, podemos concluir que quando estamos falando de inclusão escolar precisamos pensar em outro "modelo de escola", pois o que aí está continua a excluir, até mesmo inconscientemente as pessoas com deficiência, transtorno global do desenvolvimento, altas habilidades e superdotação. O ideal seria que todas as escolas regulares fossem inclusivas, onde os alunos com deficiência não fossem ignorados, excluídos, segregados do ambiente de ensino e aprendizagem. Dessa forma, concluímos que quando estamos falando sobre inclusão escolar, estamos falando de 
outro modelo de escola, pois este modelo em que as professoras relatam continua a segregar as pessoas com deficiência do ambiente de aprendizagem.

\section{SCHOOL INCLUSION: SOME DISCUSSIONS IN MATHEMATICS EDUCATION}

Abstract: This article presents considerations about laws, dissertations and theses in the Graduate Program in Mathematics Education discussing this topic and some reflections on school inclusion from clippings of stories of teachers who teach mathematics in a municipality of São Paulo, Rose survey participants (2014). In this research were interviewed nine teachers, seven teachers of Mathematics and two teachers of Special Education. To provide these narratives was used as the methodology of Oral History. At the end we find that when we are talking about school inclusion, we are talking about another "school model", as this where the teachers report and that there is still the rule, even unconsciously people with disability, pervasive developmental disorder, high abilities and giftedness

Key words: Inclusive education mathematics. School. Students with disabilities. Teachers. Narratives.

\section{REFERÊNCIAS}

BENDES, N. de O. Vigotski e a educação especial: notas sobre suas contribuições. Revista Cocar, Belém, v.4, n.7, p.86-92, 2010. Disponível em: <http://paginas.uepa.br/seer/index.php/cocar/article/viewFile/41/31>. Acesso em: 24 jun. 2016.

BRASIL. Ministério da Educação. Secretaria de Articulação com os Sistemas de Ensino. Planejando a próxima década: conhecendo as 20 metas do Plano Nacional de Educação. Brasília, 2014. Disponível em:

<http://pne.mec.gov.br/images/pdf/pne_conhecendo_20_metas.pdf>. Acesso em: 16 jun. 2016.

BRASIL. Ministério da Educação. Programa Educação Inclusiva: direito à diversidade no contexto da SECADI/MEC. Brasília, 2013. Disponível em: $<$ http://portal.mec.gov.br/index.php?option=com_docman\&view=download\&alias $=136$ 73-8-programa-ed-inclusiva-direito-a-iversid-profa-simone-mpdf\&category_slug=julho-2013-pdf\&Itemid=30192> . Acesso em: 16 jun. 2016.

BRASIL. Decreto $n^{\circ} 7611$, de 17 de novembro de 2011. Dispõe sobre a educação especial, o atendimento educacional especializado e dá outras providências. Diário Oficial da União, Brasília, 18 nov. 2011. Disponível em: <http://www.planalto.gov.br/ccivil_03/_Ato2011-2014/2011/Decreto/D7611.htm> Acesso em: 16 jun. 2016. 
BRASIL. Conselho Nacional de Educação. Resolução no 4, de 2 de outubro de 2009. Institui diretrizes operacionais para o atendimento educacional especializado na educação básica, modalidade educação especial. Brasília, 2009. Disponível em: <http://portal.mec.gov.br/dmdocuments/rceb004_09.pdf > Acesso em: 16 jun. 2016.

BRASIL. Ministério Público Federal. $\mathrm{O}$ acesso de alunos com deficiência às escolas $\mathrm{e}$ classes comuns da rede regular. 2. ed. Brasília, DF. 2004. Disponível em:

<http://www.adiron.com.br/site/uploads/File/cartilhaatual.pdf $>$. Acesso em: 16 jun. 2016.

BRASIL. Ministério da Educação. Secretaria de Educação Especial. Decreto n 3.298, de 20 de dezembro de 1999. Regulamenta a Lei no 7.853 de 24 de outubro de 1989. Dispõe sobre a Política Nacional para Integração da Pessoa Portadora de Deficiência, consolida as normas de proteção e dá outras providências. Diário Oficial da União, Brasília, 1999. Disponível em: <http://portal.mec.gov.br/seesp/arquivos/pdf/dec3298.pdf>. Acesso em: 16 jun. 2016.

BRASIL. Lei ${ }^{\circ}$ 9.394, de 20 de dezembro de 1996. Estabelece as diretrizes e bases da educação nacional. Diário Oficial [da] União, Brasília, DF, 23 dez. 1996. Seção 1, p. 1.

BRASIL. Declaração de Salamanca e linha de ação sobre necessidades educativas especiais. Brasília: CORDE, 1994a.

BRASIL. Ministério da Educação e Cultura. Secretaria de Educação Especial. Política Nacional de Educação Especial. Brasília, 1994b. Disponível em:

<http://www.dominiopublico.gov.br/download/texto/me002472.pdf>. Acesso em: 16 jun. 2016.

BRITE, R. B.; SOBRINHO, F. de P. N.; CASTELÕES, D. Concepções de gestores sobre pessoas com deficiência: trabalhadores de uma rede de supermercados. In: MENDES, E. G.; ALMEIDA M. A. (Org.). Das margens ao centro: perspectivas para as políticas e práticas educacionais no contexto da educação especial inclusiva. Araraquara: Junqueira \& Marin, 2010. v.1. p. 443-454.

CALORE, A. C.de O. As ticas de matema de cegos sob o viés institucional: da integração à inclusão. 2008. 120f. Dissertação (Mestrado em Educação Matemática) Universidade Estadual Paulista, Rio Claro, 2008.

CANDAU, V. M. Construir ecossistemas educativos-reinventar a escola. In:

CANDAU, V. M. (Org.). Reinventar a escola. 5.ed. Petrópolis: Vozes, 2007. p.111.

CANDAU, V. M. Cotidiano escolar e cultura(s): encontros e desencontros. In: CANDAU, V. M. (Org.). Reinventar a escola. Petrópolis: Vozes, 2000. p.61-78.

CANDAU, V. M. (Coord.). Somos todos iguais? escola, discriminação e educação em direitos humanos. Rio de Janeiro: DP\&A, 2003.

GRUPO DE HISTÓRIA ORAL E EDUCAÇÃO MATEMÁTICA. Sobre o Ghoem. Universidade Estadual Paulista, Faculdade de Ciências, Bauru, [2016]. Disponível em: 
$<$ http://www2.fc.unesp.br/ghoem/index.php?pagina=sobre.php>. Acesso em: 16 jun. 2016.

HILSDORF, C. R. R. Educação matemática em escolas inclusivas: a sala de recursos em destaque. 2014. 112 f. Dissertação (Mestrado em Educação Matemática) - Instituto de Geociências e Ciências Exatas, Universidade Estadual Paulista, Rio Claro, 2014.

LIRIO, S. B. A tecnologia informática como auxílio no ensino de geometria para deficientes visuais. 2006. 115 f. Dissertação (Mestrado em Educação Matemática) Instituto de Geociências e Ciências Exatas, Universidade Estadual Paulista, Rio Claro, 2006.

MARCELLY, L. Do improviso às possibilidades de ensino: estudo de caso de uma professora de matemática no contexto da inclusão de estudantes cegos. 2015. 192f. Tese (Doutorado em Educação Matemática) - Instituto de Geociências e Ciências Exatas, Universidade Estadual Paulista, Rio Claro, 2015.

MARCELLY, L. As histórias em quadrinhos adaptadas como recurso para ensinar matemática para alunos cegos e videntes. 2010. 141f. Dissertação (Mestrado em Educação Matemática) - Instituto de Geociências e Ciências Exatas, Universidade Estadual Paulista, Rio Claro, 2010.

MARCONE, R. Deficiencialismo: a invenção da deficiência pela normalidade. 2015. 170 f. Tese (Doutorado em Educação Matemática) - Instituto de Geociências e Ciências Exatas, Universidade Estadual Paulista, Rio Claro, 2015.

MARCONE, R. Educação matemática inclusiva no ensino superior: aprendendo a partilhar experiências. 2010. 126f. Dissertação (Mestrado em Educação Matemática) Instituto de Geociências e Ciências Exatas, Universidade Estadual Paulista, Rio Claro, 2010 .

MENDES, E. G. Pesquisas sobre inclusão escolar: revisão da agenda de um grupo de pesquisa. Revista Eletrônica de Educação: Reveduc, São Carlos, v. 2, n. 1, p. 3-25, 2008.

MOURA, A. Q. Educação Matemática e crianças surdas: explorando possibilidades de um cenário para investigação. 2015. 132 f. Dissertação (Doutorado em Educação Matemática) - Instituto de Geociências e Ciências Exatas, Universidade Estadual Paulista, Rio Claro, 2015.

MOREIRA, A. F. B.; CANDAU, V. M. Educação escolar e cultura(s): construindo caminhos. Revista Brasileira de Educação, Rio de Janeiro, n. 23, p. 156-168, maio/ago. 2003.

O'BRIEN, J. ;O'BRIEN, C. L. A inclusão como uma força para a renovação da escola. In: STAINBACK, S.; STAINBACK, W. Inclusão: um guia para educadores. Artes Médicas: Porto Alegre, 1999. p.40-61.

OLIVEIRA, J. C. G. Uma proposta alternativa para a pré-alfabetização matemática de crianças portadoras de deficiência auditiva. 1993. 94 f. Dissertação (Mestrado em 
Educação Matemática) - Instituto de Geociências e Ciências Exatas, Universidade Estadual Paulista, Rio Claro, 1993.

OSÓRIO, A. C. do N. Escolarização: práticas sociais, culturais e pedagógicasFragmentos de uma realidade seletiva. In: MENDES, E. G.; ALMEIDA M. A. (Org.). Das margens ao centro: perspectivas para as políticas e práticas educacionais no contexto da educação especial inclusiva. Araraquara: Junqueira \& Marin, 2010. v.1. p.89-98.

PADILHA, A. M. L. Desenvolvimento cultural e educação escolar: aporte teórico para pensar o desenvolvimento psíquico do deficiente intelectual. In: OMOTE, S.; OLIVEIRA, A. S. de; CHACON, M. C. M. (Org.). Ciência e conhecimento em educação especial. São Carlos: Marquezine e Manzini: ABPEE, 2014. p.100-115.

PASSOS, A. M.; PASSOS, M. M.; ARRUDA, S. de M. A Educação matemática inclusiva no Brasil: uma análise baseada em artigos publicados em revistas de educação matemática. Revista Brasileira de Ensino de Ciências e Tecnologias, Ponta Grossa, v.6, n. 2, p.01-22, mai-ago. 2013.

PLETSCH, M. D. Repensando a inclusão escolar: diretrizes políticas, práticas curriculares e deficiência intelectual. Rio de Janeiro: Edur, 2010.

ROCHA, L. P.; FIORENTINI, D. Percepções e reflexões de professores de matemática em inicio de carreira sobre seu desenvolvimento profissional. In: FIORENTINI, D.; GRANDO, R. C.; MISKULIN, R. G. S. Práticas de formação e de pesquisa de professores que ensinam matemática. Campinas, SP: Mercado de Letras, 2009. p.120145 .

RODRIGUES, O. M. P. R. Educação especial: história, etilogia, conceitos e legislação vigente. In: CAPELLINI, V. L. M. F. (org.) Práticas em educação especial e inclusiva na área da deficiência mental. Bauru: MEC/FC/SEE, 2008. p.03-35.

ROMERO, R. A. S.; SOUZA, S. B. Educação inclusiva: alguns marcos históricos que produziram a educação atual. In: CONGRESSO NACIONAL DE EDUCAÇÃO: FORMAÇÃO DE PROFESSORES, 8.; CONGRESSO IBERO-AMERICANO SOBRE VIOLÊNCIA NAS ESCOLAS, 3., 2008, Curitiba. Anais... Curitiba: EDUC, 2008. Disponível em:

<http://www.pucpr.br/eventos/educere/educere2008/anais/pdf/447_408.pdf>. Acesso em: 16 jun. 2016.

ROSA, E. A. C. R. Professores que ensinam matemática e a inclusão escolar: algumas apreensões. 2014. 160 f. Dissertação (Mestrado em Educação Matemática) Instituto de Geociências e Ciências Exatas, Universidade Estadual Paulista, Rio Claro, 2014.

ROSA, F. M. C. da. Professores de matemática e a educação inclusiva: análises de memoriais de formação. 2013. 182 f. Dissertação (Mestrado em Educação Matemática) - Instituto de Geociências e Ciências Exatas, Universidade Estadual Paulista, Rio Claro, 2013. 
SALES, E. R. de. A visualização no ensino de matemática: uma experiência com alunos surdos. 2013. 235f. Tese (Doutorado em Educação Matemática) - Instituto de Geociências e Ciências Exatas, Universidade Estadual Paulista, Rio Claro, 2013.

SILVA, M. M. da S.; SANTOS, A. P. dos. Educação inclusiva: considerações sobre políticas públicas e formação de professores. In: RAHME, M. M. F. FRANCO, M. A. M. DULCI, L. C. (Orgs.). Formação e políticas públicas na educação: tecnologias, aprendizagem, diversidade e inclusão. Jundiaí: Paco, 2014. p.216-250.

VIGOTSKI, L. S. Defektologuia i utchenie o razvitii i vos-pitanii nenormálnogo rebionka. In: Problemi defektologuii [Problemas de defectologia]. Moscou: Prosveschenie, 1995. p. 451-458.

VITALIANO, C. R.; VALENTE, S. M. P. A formação de professores reflexivos como condição necessária para a inclusão de alunos com necessidades educacionais especiais. In: VITALIANO, C. R. (Org.). Formação de professores para a inclusão de alunos com necessidades educacionais especiais. Londrina: EDUEL, 2010. p. 100-129. 